\title{
Into the Abscess: A 50 Year-Old Man with Empyema Necessitans
}

\section{Avraham Zvi Cooper*, Jennifer Sawaya and Jared Grochowsky}

Avraham Zvi Cooper, Medical Resident, Beth Israel Deaconess Medical Center,, Internal medicine, USA

A 50-year-old man presented with two months of malaise, weight loss, and back pain after an accidental aspiration. Labs showed a neutrophilic leukocytosis of 23,000/uL. Imaging revealed a large pleural and paraspinal fluid collection (Figures 1-3), extending down to the pelvis, consistent with empyema necessitans and paraspinal

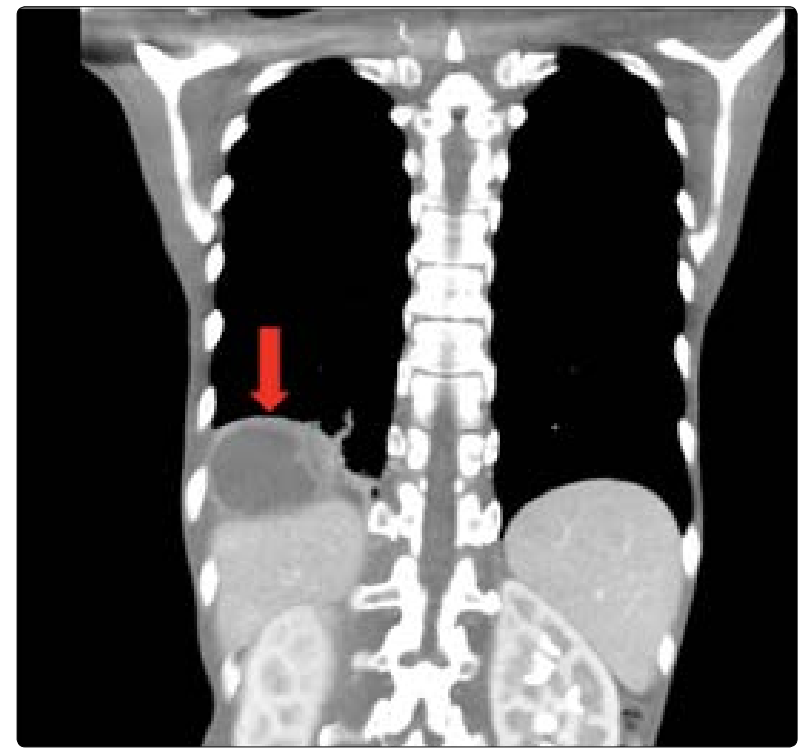

Figures 1: Coronal chest CT views showing a complicated right-sided basilar pleural and paraspinal fluid collection (red arrows) consistent with empyema necessitans.

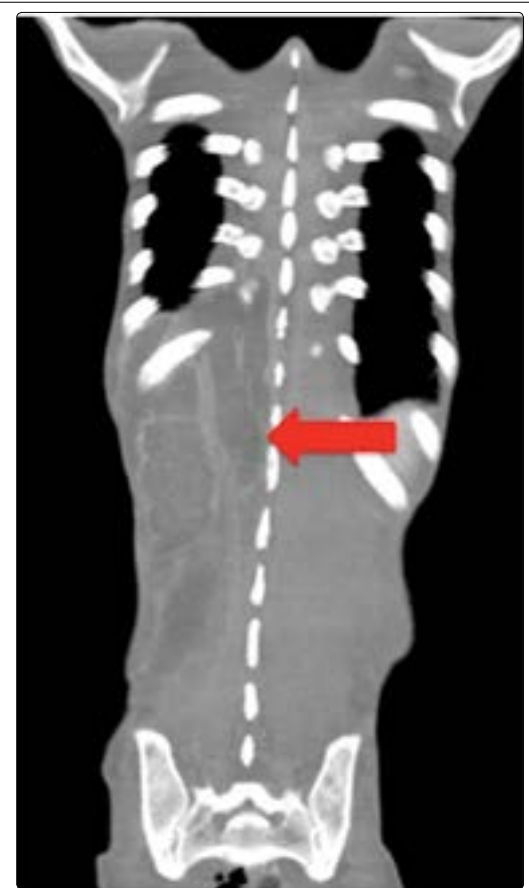

Figures 2: The collection extends from the chest wall to the pelvis. abscess. Cultures grew Streptococcus anginosus (also known as Strep. milleri). He received antibiotics and drainage, with course complicated by malnutrition, tracheostomy, and encephalopathy. His care was eventually transitioned to comfort-focused. Commonly causing brain and abdominal abscesses, $S$. anginosus uncommonly causes empyema, usually from aspiration [1]. It produces hyaluronidase, allowing for liquefaction of and extensive spread through tissues [2].

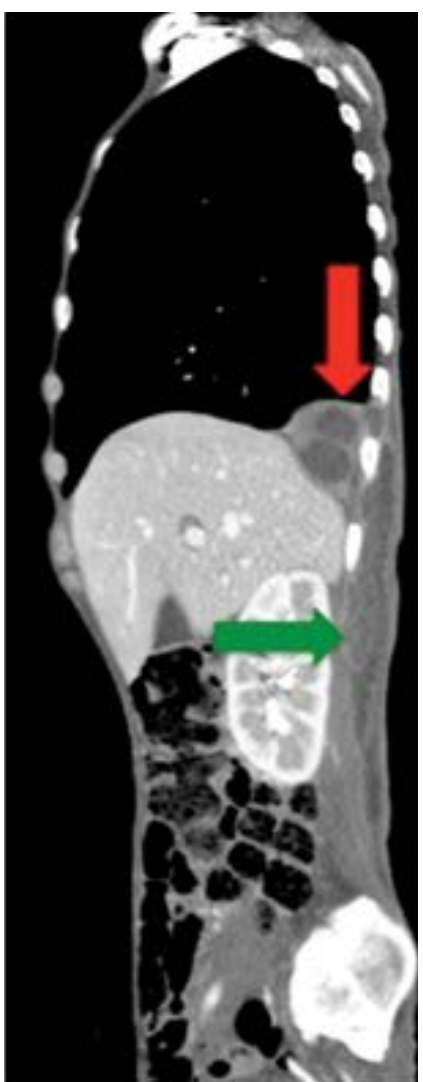

Figure 3: Extension of the fluid collection (red arrow) into the thoracic and lumbar paraspinal soft tissues (green arrow) as seen on sagittal chest CT.
*Corresponding author: Avraham Zvi Cooper, Medical resident, Beth Israe Deaconess Medical Center, Internal Medicine, 330 Brookline Ave, Boston, MA 02215, USA, Tel: 6178178406; E-mail: acooper2@bidmc.harvard.edu

\section{Received March 29, 2015; Accepted April 15, 2015; Published April 20, 2015}

Citation: Cooper AZ, Sawaya J, Grochowsky J (2015) Into the Abscess: A 50 Year-Old Man with Empyema Necessitans. J Pulm Respir Med 5: i017. doi:10.4172/2161-105X.1000i017

Copyright: () 2015 Cooper AZ. This is an open-access article distributed under the terms of the Creative Commons Attribution License, which permits unrestricted use, distribution, and reproduction in any medium, provided the original author and source are credited. 
Citation: Cooper AZ (2015) Into the Abscess: A 50 Year-Old Man with Empyema Necessitans. J Pulm Respir Med 5: i017. doi:10.4172/2161105X.1000i017

\section{References}

1. Marinella MA, Harrington GD, Standiford TJ (1996) Empyema necessitans due to Streptococcus milleri. Clin Infect Dis 23: 203-204.
2. Jacobs JA, Stobberingh EE (1995) Hydrolytic enzymes of Streptococcus anginosus, Streptococcus constellatus and Streptococcus intermedius in relation to infection. European Journal of Clinical Microbiology and Infectious Diseases 14: 818-820 